\title{
The Dichotomy of Proliferating Information Technology in Globalization of Education: A Case Study
}

\author{
Sri Herminingrum \\ Faculty of Cultural Studies, Universitas Brawijaya, Indonesia \\ Email: hermien_18@ub.ac.id
}

\begin{abstract}
The Information Technology (IT) proliferation path cannot be separated from the role of American young entrepreneurs who generate revolutionary change in global information system. This modern existence, of course, leads to the socio-cultural phenomena encompassing dichotomous trends in many aspects of Indonesian daily lives, not to mention in education world. Scrutinizing the data obtained from a one-semester direct observation, structured interview, and questionnaire distribution to 586 students of 11 faculties at Universitas Brawijaya is used as the base of a case study. By employing qualitative method, therefore, the study aims to provide insights about the merits and demerits of the use of IT in globalization of education, which is commonly happening in Indonesia within the last decade. The result shows that the dependence of students as Indonesian digital citizen on the internet-based information tends to impact negatively on the basic values of education, such as influencing the students to be narrow-minded, self-centered, and preferring to gain instant results.
\end{abstract}

Keywords: Information Technology; dichotomous trends; globalization of education

\section{INTRODUCTION}

In the frame of civilization, education represents the core in the process of shaping culture. Since the groundwork of culture by its nature cannot be repudiated from human values, the cultural changes in education world become more complex and less obvious. This unavoidable dynamic change has been predicted by du Guy (in Hall and du Guy, 2013) as the reason why the ongoing cultural changes are always parallel with globalization process, and turn to be a dominating theme of scientific discussions within social and humanity studies in academic world

Globalization, which can be defined as the relationship between some different geographical areas, has been detected since the $13^{\text {th }}$ century when different countries from various parts of the world interact massively. However, the intensifying inter-nation relations have created some by-products of other cultural interests. Historically, this century is the beginning of economy-cultural and political-cultural exchanges between the East and the West: the great Imperium of Rome and Greece with China or other Eastern territories (Chaubet, 2015), with trading as the main reason. In the line with its theme, globalization from the late 1980's became "a topic of a great political and economy policy concern and, ... one of the most frequently used terms in political and business discourse. In turn, globalization penetrates the discourse of ideological and everyday life" (Robertson in Ritzer and Smart, 2003). It is not an abrupt cultural issue because life experiences and systematic ideas which are covered as ideology are growing along with the practical activities in life, including in education.

Therefore, culture is always positioned in an abstract context and subjective understanding because it is shaped by people to be accepted based on spatial and temporal dimensions. As a building, culture appears 
in a continuous movement between deconstruction and reconstruction. This process was argued by Street (1993: 23-43) and reached a conclusion that the dynamic property of culture causes it to be inherent to the shift, transformation, or even changes of cultural values to adjust to various space and time. This concept is suitable with the process of today's globalization used to describe the situation of the world, whereby its parts linked with each other.

The three key aspects which are used as the basis of the globalization framework, the formation of mobility system, a single scale, and solid networks; accelerate the progressive cross-border process among countries. Through the passage of time, the advancement of technology, be it in transportation, information, or communication, has unified countries of the world within one mutual understanding. The reality is that the development of technology which is strongly associated with the 'West', or in this case is America, has proved its power.

Accordingly, the discourse of ideology and everyday life in terms of globalization asserted by Robertson (2003) makes social and cultural studies exist within a scope which relates to many subjects, main agent, and the cultural manifestation itself. A remarkable example, today, can be observed from the cultural changes of an individual, groups, or society as the response to the rapid current of modern technology. Then, there will be two groups with distinct category: the active; the ones who hold the mastership in modern technology; and the passive; those who only use the products of the masters As such, they are Americans and Indonesians.

Considering the shifts of human values as the foundation of education which overlap with the problems that arise due to these differences, this paper tries to portray the cultural changes of the use of Information Technology or IT in the education system in Indonesia by performing a case study. The scrutiny to IT usage by Indonesian students, either its merits or demerits, is significant to do because the more the new technologies used, the more hectic the pace of life aspects are. This state is not merely experienced by users but very likely by consumers, such as happening in Indonesian academic life when students become the habituated users as well as consumers of IT.

Along with the history of globalization, the American role in assembling borderless countries throughout the world is because of its power on the present technology advances. This achievement of course is the working out of American traditional values inherited from the past, which have been sustaining the nation and the American young generations who always live up to it. To a certain degree, the notion of 'inventiveness and the can-do spirit' cannot be detached from the frontier heritage because it teaches Americans on self-reliance. Since Americans found the New Land "frontier men and women not only had to provide most of their daily life essentials, but they were also constantly facing new problems and situations which demanded new solutions" (Datesman, Crandall and Kearny, 2005: 77). Pioneers bequeathed American new generations on how to learn to experiment with new ways of doing things. This sense of optimism leads to the construction of one of the American traditional values: 'hard work'.

Today, as the provider of all forms of new technology, Americans create important innovations as the effect of spreading the spirit of inventiveness. The everlasting effort to experiment and invent lead the young Americans to be entrepreneurs of integrity who have broken the walls that set apart countries throughout the world. The burgeoning IT created by the young Americans has succeeded not only in fostering American traditional values but also in seizing global digital citizens. This is manifested by "2002 young innovators under 35' and under 30' who are changing the world' (Howard, 2014) in internet-based technology. The most priceless credit of this kind of revolution is 'efficiency', one of the characteristics of rationalization process. A process which "leads to society in which a great deal of emphasis is placed on finding the best or optimum means to any given end"; and "a wide-ranging process of rationalization is occurring across American society and is having an increasingly powerful impact in many other parts of the world" (Ritzer, 1983: 100-101).

Power, in the scope of globalization, more or less signifies to the world's polarization, visualized by half and half domain of 'East' and 'West' whose traits are different. If this concept of difference between East: Indonesia, and West: America, is inserted in cultural context, the outcome is the construction of dichotomy. Dichotomy itself is frequently termed as bipartition because it covers two meanings: (1) 'Jointly exhaustive', meaning that everything must strictly be grouped to one part or the other; and (2) 'Mutually exclusive', because nothing can be categorized into the two parts at the same time (Cryer, 2017). These two ideas embrace Indonesian position as a part of the East but at the same time it cannot be separated from the West, America, as the center of power in mastering technology.

It is, therefore, an interesting topic to be discussed when this criterion relates to homogenization of the worldwide IT usage and dichotomous impacts on higher 
education in Indonesia through humanism approach. The surfacing of the paradoxical focus from the development of technology between America as a powerful producer and Indonesia as a consumer absolutely adopting the idea of dichotomy. What happens when the dichotomy of global culture in its relationship with IT penetrates the world of education which main substance is always linked with humanity?

The process of education does not solely concern with knowledge, but it is integrated with other components which the prominent one is humanity. The inherence of human values in education is unquestionable as long as the basis of education itself still bounds to the enhancement both of mind and character. On this account, the case study performed to observe how the impacts of utilizing IT towards the students of Universitas Brawijaya $^{2}$, as a group representing the academic society. They are selected to be the subjects of the research. Their role as the considerable agents taking part in the sociocultural change recently can be used as an indicator of how the use of internet-based technology influences the students of higher education.

To meet the aim of the study, a direct observation has been executed in daily routine class during one semester, with eight classes targeted out of the 11 faculties observed. In addition, structured interviews are held and strengthened by giving limited but measured questionnaire to validate the collected data. Qualitative method is used in expectation of uncovering the merits and demerits of the IT used by the students of Universitas Brawijaya.

\section{DISCUSSION}

When globalization is related to culture-economy and culture-politics, it gives a meaning as "global capitalism" (Appadurai, 2010). Previously, social transformation as the impact of globalization was also identified by Robertson (2003: 461):

The rapid spread subsequently of organized global capitalism ....... The economic is becoming cultural and the cultural is becoming economic. The emphasis upon the different forms of capitalism is closely intertwined with what has often been cast as 'the cultural turn'. The latter is itself bound up with the matter of commodification.

Today, globalization in which the development of technology becomes a prerequisite for global relationship, attributes to economic, cultural, and political interests. Subsequently, it has created dramatic change in all aspects of human values including in education. Of course, this idea cannot be separated from cultural context as "an age of consumerism": the era where the producer and consumers are racing to fulfill the demands of globalism. Consumerism is one of the most significant cultural phenomena in modern lifestyle. This is hastened by the impressive growth of economy and the advancement of technology which engenders the fading away of spatial and temporal barriers.

The published research results postulated that the dissolving borders between countries all over the world due to globalization is an intensification of the social interactions between global citizen of the world. "... social relations which link distant localities in such a way". In short, in the process of globalization, cultural changes can be regarded as an impact of social transformation and vice versa (Giddens, 1990: 4). These changes are sped up by the spreading of the advanced technology throughout the world. In his scientific conception, Ritzer (1998) also discussed about the role of technology in globalization and its impact towards the aspects of social and cultural life of global society in America. Globalization which builds the concept of homogenization via the fast development of IT, indeed, can be also easily found in numerous Indonesians' daily life, covering most of the education system in Indonesian universities.

Through rationalization process emphasizing efficiency, predictability, calculability, substitution of non-human for human technology, as well as control over uncertainty, IT enables to structure the uniformity of the education system. Exemplified by the reason of rational, countable, and certain; values, as the essence of education, is conveniently ignored. Qualitative judgments have been taken over technological machines because they can calculate objectively. Equipped with the connection between theory and culture especially in terms of consumption and globalization that reach the higher education society, this phenomenon gives a warning. The bombardment of IT and the application of its products in higher education is affirmed as an "irrational" academic activity (Ritzer,1983: 106). His research at some modern American universities established that academic environment has transformed into factory. Those who normally should be interacting change dramatically because humans are shaped into rapidly operating industrial machines called internet.

Internet-based technology has changed the salient point for globalization of education. Two-way communication between the professors, or lecturers, with the students which aimed to develop intelligence, mind, and character, has perished. The human values 
which strengthen the intellectual balance as a supporting pillar of the education system has become less sturdy. There is no humanized room for elaborating different views positively or having two directional discussion that is open for dialectic thoughts, which will propel students to solve a problem without leaving academic ethics and values. Education aspects are all quantified due to the enhancement of technology; computerized scoring, internet-based materials, online instructions, and virtual classes. IT spoiled the students with the myriads of information that are unfortunately proven to be mostly inaccurate. Students tend to take short-cut paths to get the desired results as soon as possible, without any process of critical thinking to achieve qualified education.

If education is the representation of the civilization, the values of moral ethics embedded in education underscores human virtue. In accordance with that, Aristotle theorized that the outcome of education process ideally encompasses two values: the moral and the intellectual. Humans with characters as the expected output of higher education are supposed to be the men of understanding and good temper. This conception arises since the intellectual virtues involve reason, they belong to that rational part of the soul which gives commands by its possession of reason, while the moral belong to the part which is irrational but by its nature obedient to the part possessing reason. (Barnes and Kenny, 2014: 49)

These qualitative values are very different with the globalization of education emphasizing on the role of reason that surely is quantitative by nature. Hence, to trace the impact of the use of IT in education towards the appreciation to academic ethics and values, the preference and frequency of internet-based technology usage by the students of Universitas Brawijaya is used as the case study. This aims to elucidate a prototype of the tendency of the modern education that currently is taking place in Indonesia. The subjects are the students from 11 out of the total 15 faculties within Universitas Brawijaya - with the total number of 598 people, as seen in the table 1.

As supporting data, questionnaires are distributed to every two classes of the 11 faculties or departments investigated, with 16 to 36 students of each group. There are 586 respondents who completed the answers, whereas 3 gave incomplete responses. In terms of the four importance level categories of the role of internet in academic life, 476 students (81.22\%) said that this modern technology is very important, 98 students $(16.72 \%)$ said it is important, 11 students $(1.9 \%)$ answered it as moderately important, and only 1 student responded that it is not too important. The existing answers were then correlated
Table 1. The Subjects of the Case Study

\begin{tabular}{|c|c|c|c|c|}
\hline \multirow{2}{*}{$\begin{array}{c}\text { No. } \\
1 .\end{array}$} & \multirow{2}{*}{$\begin{array}{l}\text { Faculty (Department) } \\
\text { Medicine (Nursery) }\end{array}$} & \multicolumn{2}{|c|}{ Class } & \multirow{2}{*}{$\begin{array}{c}\begin{array}{c}\text { Participants } \\
\text { (Students) }\end{array} \\
60\end{array}$} \\
\hline & & 26 & 24 & \\
\hline 2. & $\begin{array}{l}\text { Natural Sciences } \\
\text { (Chemistry \& Physics) }\end{array}$ & 18 & 24 & 42 \\
\hline 3. & Veterinary and Medicine & 18 & 16 & 34 \\
\hline 4. & $\begin{array}{l}\text { Cultural Studies } \\
\text { (Chinese \& Japanese) }\end{array}$ & 20 & 28 & 48 \\
\hline 5. & Law & 36 & 24 & 60 \\
\hline 6. & $\begin{array}{l}\text { Fisheries and Marine } \\
\text { Sciences (Water } \\
\text { Resources Management) }\end{array}$ & 32 & 32 & 64 \\
\hline 7. & $\begin{array}{l}\text { Social Sciences } \\
\text { (Communication) }\end{array}$ & 27 & 28 & 55 \\
\hline 8. & Agriculture (Agronomy) & 32 & 26 & 58 \\
\hline 9. & Food Technology & 25 & 28 & 53 \\
\hline 10. & $\begin{array}{l}\text { Economics and Business } \\
\text { (Management) }\end{array}$ & 32 & 20 & 52 \\
\hline 11. & $\begin{array}{l}\text { Engineering (Industrial } \\
\text { Engineering) }\end{array}$ & 36 & 36 & 72 \\
\hline & TOTAL & 302 & 296 & 598 \\
\hline
\end{tabular}

with the comparison between two choices about the use of internet-based technology to increase their knowledge. The choices are:

1. The frequency of internet usage as an information source; and

2. The frequency of internet usage as a lifestyle in accordance with the demand of global culture.

One-semester direct observation was performed in eight classes ranging from the second to the sixth semester to explore students' habits in using IT facilities. Simultaneously, interviews were also held by random sampling method in these classes to support the data obtained from the study. The seven questions given, then, were abstracted into two main problems: the role of internet and its connection with academic activity as a main source of gaining knowledge. Additionally, a question relating to reading habits which sources can be taken either from internet (e-books) or printed books ${ }^{3}$ was asked by consideration that this activity is the ground of intellectuals: the basis of critical thinking. A thesis proposing that reading habits is a step of mark to construct human capital. The competence of reading makes one of the basic dimensions improving human development through education, as well as the competence writing, numeration, science, financial, digital, culture and citizenry (Sunendar, 2018). Therefore, it underlines the 
reason why the fact of students' preference in reading habits cannot be neglected.

Research by Fingon (2012: 90) found that the reluctance of the students to conduct reading activity is commonly due to "...lack interest and motivation in reading and have fallen behind, experiencing the cycle of failure." This shows that the barrage of failures will simultaneously reduce their chances to reach success. Therefore, as proposed by Frey (cited in Fingon, 2010) "as young adolescents get older, they need to be able to analyze what they read and perceive themselves as active users in order to comprehend texts." Most likely, the considerably low interest of the students of Universitas Brawijaya on reading textbooks has been resulted since they entered the age of reading phase. When they get into the higher education institution, this initial condition is worsened by the easiness and availability of the information sources from the internet. Consequently, they are located beyond the notion of critical thinking.

In accordance with the frequency of the internet usage, the information gained from distributed questionnaires (Figure 2) illustrates that 536 students, or $91 \%$, cannot separate from their daily routines with IT. Only 53 students or $9 \%$ assure that they are not dependent much on internet-based technology. Moreover, when the high frequency of internet usage by students is correlated with the results of the observation which is supported by the interview, it does not correspond with a high interest for reading.

As it is shown in figure 1, approximately 403 or $68 \%$ of the whole students uses the internet for leisure or merely updating their social media. They rarely use IT services for checking online announcements, such as rescheduled class, assignment, or other academic instructions given by their lecturers or academic staff. It is not an impossible thing if a classroom has changed into a place to exchange text messages between friends, selfie, chatting, Insta story, even operating video games applications or just looking for a power source to charge their mobile phones' battery. Different from this group, a small number of students, 186 or $32 \%$, use this modern technology in the correct way as its function, such as searching scientific articles, validating various information, doing assignments based on internet sources, or networking for academic discussions.

Seeing the ratio of the students' preference on IT, it can be affirmed that the use of the latest internet-based technology by students does not connect directly with the students' critical thinking. Compared to the ones who are addicted to social media, the small numbers of students who function IT as an aid to broaden their knowledge

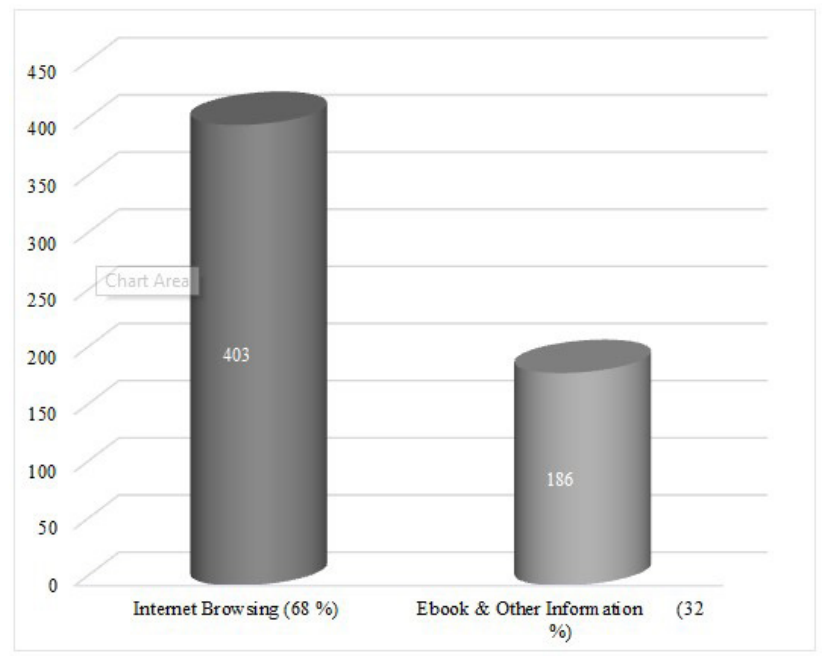

Figure 1. Students' Preference on IT

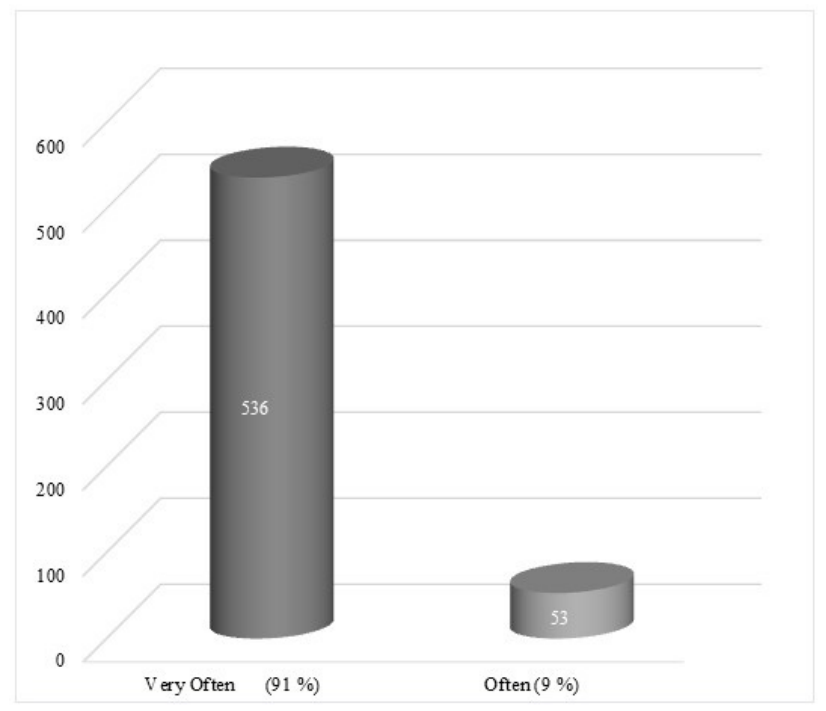

Figure 2. Frequency of Internet Usage

positively are the expected global future generation. Regardless the unhealthy imbalance ratio, Indonesian young generation, represented by the students who participate in the research, can be categorized as the ITliteracy generation. They are Indonesian digital citizen.

The data obtained from the study depict an imposing direction of how the use of social media is becoming a priority for socialization among students and Indonesian young generations in general. Social media have predominant role in absorbing them into 'global relation' lifestyle. This confirms the finding of Nielsen Media Research which ranks Indonesia in one of the top 5 countries of internet and social media users. The users of social media, mostly students, are being trapped in a 
manipulated world. Deep down, they are not prepared to face 'the power of media' served by digital technology. Instead of using social media for networking to explore their academic potential, students of Universitas Brawijaya use them as a means of socializing in inessential matters such as gossiping, talking over trivial things, or showing off individual concerns.

Even though definition on 'social media' posited by Wildman and Obar (2015: 5) is unclear, this terminology generally attributes to 'social network'. "Social media services enable new forms of socialization that, when successful, can become integral to the daily lives of million people" without the exception of the numerous young Indonesians as global citizens. Facebook and Twitter, two of the primary social media platforms, are the most popular media used by the students observed. These fascinating internet-based applications are increasingly creating links among them within virtual space. Even though there is a subtle difference in meaning between social media and social networking, a lot of internet users oftentimes use the terms interchangeably. As far as there are positive benefits, this internet-based technology functions as social networking; for instance: to efficiently control market operation, monitor business performance, trace actual new scientific findings, or increase government's public services. The capability of IT in providing information in a very short time at low cost makes global information barriers reduced. The function both of social networking and social media however, evokes a vast effect on socio-cultural life in Indonesia. And, because most Indonesians do their activities by strongly rely on the applications served by internet-based technology, they are not users anymore but transform to be consumers.

Different from Indonesians who belong themselves to the group or community of users and consumers of IT, Americans have their own track-record in advancing technology. The driving force of American control over the world is its power of economy and technology; and its energy source is the young generations. Their success in playing their role in these two spaces attach inherently to the root of American Dream: traditional values that lead Americans to gain their dreams. This idealism, particularly the idea of self-reliance, has been manifested and preserved until now through the spirit of competitiveness and optimism.

American young innovators of IT who create various software for social media, among other pioneered by Larry Page: the co-founder of Google, followed by innovators such as Jack Dorsey for Twitter and Square, Chad Hurley for YouTube, Mark Zuckerberg for Facebook, and Jan Koum for WhatsApp, have contributed to global exchange of ideas and information. Their innovations open the barrier of time and space not merely in minute but second; a profound effect for America to control the world. As Appadurai's 5-scapes discussion on the power of technology that will "bring about new type on cultural interactions and exchanges ... which can now happen at unprecedented speeds" (Hogan, 2010). To sum up, the American young entrepreneurs' amazing breakthrough in building a huge kingdom of softwares is the key success for America in governing the popular cultural interactions and information exchanges.

Unfortunately, together with the ability of the young entrepreneurs of America to continue exploring through the introduction of a new form of IT, the students of Universitas Brawijaya potentially also continue following to use the offered virtual services. It can be said that the students experience a dramatic shift from user to militant consumer. Indirectly, they become the backbone of the developing IT, especially in consuming social-media services, which means they are the apparent power of American's business expansion of technology. In this context, the merits are at the hands of the American young entrepreneurs, i.e. material profit, and the chance to proliferate their innovations. Then, the question whether the technology advancement which accelerates globalization is a challenge or a threat for Indonesians needs more exploration to answer.

The extreme dependence on social media, the misuse of internet-based technology services which corrupts critical thinking and human values as the bases of education indicates that the students are on the state of being unable to be the subjects of their 'self'. Borrowing the philosophical and cultural commentary on the condition of this kind of modern society suggested by Edgar and Sedgwick (2008) that today, people are alienated from the notion about humanity's 'species being'4. They are powerless before the power of IT; become social media addicts and are jailed in virtual space. In the context of the research done, on the one side, the students of Universitas Brawijaya whose academic world is occupied by social media somehow are the representation of Indonesian digital citizen. On the other side, they are alienated from being humans because their everyday are controlled by a tremendously powerful machine named internet-based technology. These trends obviously depict the nature of dichotomy.

Dichotomy has currently been embraced by a part of Indonesian people and results mostly in negative impacts. This notion highlights the opinion on the contradictive effect of the globalization process put 
forward by Friedman (1994), ensuing negative and positive impacts. If the contradictive effect relates to the theory about cultural criteria, then the adoption of dichotomy concept does not stop in the polarization of East and West. The invisible things between inferior and superior or powerless and powerful are fluid because technology has melted the partition between those of criteria. Sophisticated products of technology, both of transportation and communication as well as information, are really at the hands of America. America has seized all supporting factors of globalization process. The presence of modern lifestyle based on IT in Indonesia is the manifestation of global culture. It is an example of signal success of America in playing its role as the leader dominating entire countries in the world.

Adapting with the modern lifestyle which is very dependent on IT as an equipment to reach global network is potentially increasing the number of 'bowing generation'. This label is attributed to Indonesian young generations who are busy with their own imagined world; the world where they can play with various applications served by internet-based technology. The result of the one-semester direct observation in eight classes uncovers that in their academic life, students who are extremely dependent on their own interest tend to be easy going. They are in unhealthy competition to achieve grade, as high as possible, by searching and copying the solutions of the study problems provided in internet sources. This short-cut way brings about instant result, without realizing that this is the time for artificial intelligence to take over their critical thinking. Laziness and narrow-mindedness aggressively invade students' trait. Getting high grade, rather than learning to get knowledge, are their main interest in their education process. Instant achievement drives students to utilize 'information overload'. Accordingly, plagiarism, cheating and fabrication flourish and this bad condition is aggravated by a weird judgement that it is a common trend in modern education. There is no longer trust, honesty and the honor system in education process. Self-centered behaviors for one's own pleasure will also gradually eliminate the moral-ethics teaching about respect, politeness, and the importance of helping and caring for others.

The addiction on the proliferation of advance technology is supposed to encourage "the continual obsession to own the latest innovation. ... lead to the redirecting of economic resources to feed the habit while undermining activities essential to the well-being of individuals and communities" (Bowers, 2000: 177178). Therefore, Bowers believes that the benefits of the modern technologies are seldom recognized. It is "not viewed as cultural phenomenon; rather, it is viewed from the perspective of the experts who design and integrate technologies into the existing interlocking systems". This view nourishes the simplistic thinking that technology is a common tool that consequently can be used based on intent of the user. It is also happening in Universitas Brawijaya, which utilizes the products of modern technology in ruling their education system. Benefits of the IT utilization are quantitatively earned by education institutions on account of the effectivity and efficiency reasons. But, at the same time, the invisible disadvantages haunting the students as the IT users - consumers, i.e. psychological problem, has been experienced: addiction, which everyone should be aware of. Students' academic lifestyle shaped by the internet-based technology and its new generations cannot be simply viewed as the usual cultural phenomenon.

Cultural change in education world is indeed an inevitable phenomenon that will frequently happen. It emerges in accordance with the deliberate response of people due to the pressure from their surroundings. Fave, Massimini, and Bassi (2011:23) clearly mentioned that this condition is "often intentionally directed, and actively searched for, by humans". The study findings show that in education world, the impact of global homogenization that makes use of the development of technology promotes the shortcut culture and changes the lifestyle of the users who dramatically evolve to be militant consumers. Borrowing Ritzer's phrase, there will be a great possibility that universities and higher education institutions are only going to become a production machine for their graduate scholars.

When dichotomy is translated as a single power center, the aspect of globalization that appears most prominently is the power of technology. The study discovered the negative contribution of the improper use of the internet-based service towards the human quality of students from the 11 faculties at Universitas Brawijaya. The process of education to build human capital is interrupted by the sudden, rapid technological advances. Higher education which is believed to be the significant pillar to enhance human development is now exist in superficial ways within the uniform, contemporary world. Consequently, the ideal construction is cracking, and the building is going to collapse. The civilization as the superstructure of education is falling.

Transferring knowledge, transmitting academic culture, promoting adaptation towards academic atmosphere, encouraging critical thinking, building network, increasing ethical behavior, and appreciating creativity are the main points to establish the social 
function of education (World Bank, 2008). However, the algorithm system used in technology make the components embedding with education values - culture, adaptation, and ethics (Mohamad, Tempo: 2018) deteriorate. The significant trends that these humanity components, which cannot be quantified, are declining because the idea of rationalism strongly underscores the aspects of reason, count, and certainty. That is why Ritzer (in Robertson, 2003: 13) satirically argues about human values which are torn apart from education for "values are notoriously difficult to evaluate". This statement clarifies that IT as a symbol of modernity does not always contributing positively towards education as a process to humanize humans as an actualization of civilization.

Software technology which is continuously developed by the American young innovators elevate America's control on users - consumers, in this case are Indonesians; not only by eye-witnessing but also influencing and transforming their mindset. Quoting Harari's thesis, in 21 Lessons for the $21^{\text {st }}$ Century (2018), social media have changed the way people read information. Without digesting information spreading through the means of IT, the result is disinformation. The algorithm machines transfigure to be a new dictator. The users - consumers mostly neglect the fact that information available on internet is often incomplete and even incorrect. Social media take the great portion in 'information overload' provided by internet-based technology. The applications offered make the addicts, both users and consumers, lose their capability of reasoning. They are prisoned in imagined world with crowded misleading information. Most of them are in the permanent state of lulling into fascinating cage, a virtual space. Likewise, the students of Universitas Brawijaya are suffering this kind of disease.

That is why, it is important to reconsider about human values which are inherent part of education. There is a pressing need for a socio-cultural movement to regain the notion that education is ever embedded with humanity. Students should realize that they are humanity's 'species being' who have authority to control, not to be controlled by, technology.

\section{CONCLUSION}

Information Technology (IT) has served an incredible contribution to global exchange of ideas and information. However, the role of IT in accelerating globalization should be placed in a thorough discussion within the frame of multidimension, with the emphasis on education scope that involves the values of humanity. By the reason of many unanticipated consequences suffered by most Indonesian students, such as addiction, consumer-based lifestyle, alienation, and most importantly 'information overload', the use of IT and its by-products in education is better to be recognized earlier and understood in a wise way. It is a disrupting process towards the values of everyday life even for the base of the essential future; that is education. Therefore, the results of the researches that have been done and the experts' opinion about the use of modern technology as rationalization of culture in education still need to be revisited and rethought. Technology advances which are supposedly created to help people and make their everyday activity easier in fact often bring about demerits. That of being dehumanizing and disenchanting many rational systems, the internetbased technology propels the dimming of education values which are not only based upon reasons but also on moral and ethics.

\section{ACKNOWLEDGEMENTS}

This article is an elaborated version of the paper presented in the American Studies International Conference (ASIC) held on $25-26^{\text {th }}$ October 2018 by the Faculty of Cultural Sciences, Department of Intercultural Studies, Universitas Gajah Mada. Therefore, the author thanks and appreciates the reviewer team who provides corrections and insightful suggestions, so she could make revisions to fulfill the requirements for publication in Jurnal Humaniora.

\section{ENDNOTES}

1) Refers to the frontier experience, when the first colonists settled on the east coast of the continent in 1600's. See further on American Ways: Frontier Heritage (Datesman, Crandall, and Kearney, 2005).

2) Universitas Brawijaya is a state university located in Malang - East Java, Indonesia.

3) Printed books were chosen by almost no one, with the main reason such as: it is boring, they feel lazy, it costs time, and impractical. Those answers were given to the question of "why you don't choose to read printed book as information source?".

4) This phrase is developed by Marx from a term used by philosopher Ludwig Feuerbach referring to humanity's potential to determine its own destiny.

\section{REFERENCES}

Appadurai, A. (2010). Modernity at large: Cultural Dimensions of Globalization. Minneapolis: 
University of Minnesota.

Barker, C. (2008). Cultural Studies: Theory and Practice. London: Sage Publications, Ltd.

Barnes, J. and Kenny, A. (2014). Virtue. Aristotle's Ethics: Writings from the Complete Works, pp. 48-121. New Jersey: Princeton University Press.

Bowers, C.A. (2000). Let Them Eat Data, How Computers Affect Education, Cultural Diversity, and Prospect of Ecological Sustainability. Athens: The University of Georgia Press.

Chaubet, F. (2015). Globalisasi Budaya (in Indonesian). Yogyakarta: Jalasutra.

CNN Library (2018, November 13). Mark Zuckerberg Fast Facts. Retrieved August 14, 2018, from http://edition. cnn.com/2013/05/07/us/mark-zuckerberg-fast-facts/ index.html

Cryer, A.B. Dichotomy Explained. Retrieved November 07, 2017, from https://everything.explained.today/ Dichotomy

Deb, S. (2014). Information Technology, Its Impact on Society and Its Future. Advances in Computing, 4(1), 25-29.

Datesman, M.K., Crandall, J., \& Kearny, E.N. (2005). American Ways: An Introduction to American Culture. White Plains, NY: Pearson Education.

Edgar, A. \& Sedgwick, P. (2008). Cultural Theory: The Key Concepts. New York: Taylor \& Francis Group.

Fave, A.D., Massimini, F., \& Bassi, M. (2011). Psychological Selection and Optimal Experience across Cultures: Social Empowerment through Personal Growth. Dordecht Heidelberg: Springer.

Featherstone, M., Lash, S., \& Robertson, R. (1995). Global Modernities. London: Sage Publications.

Fingon, J.C. (2012). Nontraditional Texts and the Struggling/ Reluctant Reader. Voices from the Middle, 19(4), 7075.

Friedman, J. (1994). Cultural Identity and Global Process. London: Sage Publication.

Giddens, A. (1990). The Consequences of Modernity. Cambridge: Polity Press.

Glaser, M. (2007, May 17). Twitter Founders Thrive on Micro-Blogging Constraints. Retrieved August 14, 2018, from http://mediashift.org/2007/05/twitterfounders-thrive-on-micro-blogging-constraints 137/

Hall, S. and du Guy, P. (2013). Questions of Cultural Identity. London: Sage Publication.

Harari, Y.N. (2018). 21 Lessons for $21^{\text {st }}$ Century. New York: Penguin Random House.

Hogan, A.M. (2010, September 15). Appadurai's 5-Scapes. Retrieved August 14, 2018, from https://www.amherst. edu/academiclife/departments/courses/1011F/MUSI/ MUSI-04-1011F/blog/node/229354
Horkheimer, M., \& Adorno, T. (1979). Dialectic of Enlightenment. London: Verso.

Howard, C. (2014, January 6). 30 Under 30 Who Are Changing the World. Retrieved August 14, 2018, from https://www.forbes.com/sites/ carolinehoward/2014/01/06/30-under-30-who-arechanging-the-world-2014/\#73a02f99fbfd

MIT Technology Review (2002). 2002 Young Innovators under 35: Larry Page, 29. Retrieved August 14, 2018, from http://www2.technologyreview.com/tr35/ profile.. $\mathrm{spx}$ ?TRID $=380$

Mohamad, G. (2018). Herakleitos. Majalah Tempo: Catatan Pinggir (in Indonesian), Agustus 20-26. Jakarta: Tempo Inti Media.

Nygren, A. (1999). Local Knowledge in Environment Development Discourse: From Dichotomies to Situated Knowledges. Critique of Anthropology, 19(3), 268-288. London: Sage Publications.

Pieterse, J.N. (2010). Globalization Goes in Circle: Hybridities East-West. Retrieved August 6, 2016, from https://www.researchgate.net/ publication/252220774_Globalization_goes_in circles_Hybridities_East-West

Ritzer, G. (1983). The "McDonaldization" of Society. The Journal of American Culture, 6(1), 100-107. doi: 10.1111/j.1542-734x.1983.0601 100x.

Roberts, D. (2014, October 10). How Kevin Systrom of Instagram got his start. Retrieved August 14, 2018 from http://fortune.com/2014/10/10/how-kevinsystrom-got-started/

Robertson, R. (2003). Globalization Theory 2000+: Major Problematics. Handbook of Social Theory, pp. 458471. George Ritzer and Barry Smart, (eds), London: Sage Publication.

Souppouris, A. (2013, August 8). YouTube founders remix Vine and Instagram with Mixbit for iOS. Retrieved August 14, 2018 from https://www.theverge. com/2013/8/8/4601114/mixbit-video-creationsharing-remix-ios-app-launch

Storey, J. (2010). Cultural Studies and the Study of Popular Culture. Edinburgh: Edinburgh University Press.

Sunendar, D. (2018). Menabur Spirit Literasi ke Pelosok Negeri (in Indonesian). Majalah Tempo: Inforial, Mei 21-27, Jakarta: Tempo Inti Media.

Wildman, S. \& Obar, J.A. (2015) Social Media Definition and the Governance Challenge: An Introduction to the Special Issue. Telecommunication Policy, 39(9), 1-6.

World Bank (2008). Skill Development in India: The Vocational Education and Training System. South Asia human development sector series; no. 22. Washington, DC. (C) World Bank. 